\title{
Libertarian artistic teaching. A counter-pedagogy?
}

\author{
Keywords \\ Decoloniality, Art Education, Pedagogy of the Imaginary, Teacher Training.
}

The capitalist system maintains the colonial logic in the dialogue between knowledge and ways of life. The accumulation of material wealth, individualism, production of goods and exacerbated consumption have resulted in imbalance, physical and symbolic exhaustion of the planet. The field of arts does not constitute an autonomous system in relation to culture, to the aforementioned cultural modes. In it, the processes of formation of subjects, exclusion and discrimination also result from neoliberalism, which imposes a Promethean education linked to the notion of civility and progress, causing malnutrition of feeling, sensitivity, and imagination. The poetic state is relegated to the background and restricted to literary expression. Artistic practices are inserted in the truth regimes of the hegemonic models that produce them. Building other pedagogies requires thinking about ways to deviate from the totalizing ontologies of the so-called traditional educational thought. The impact of (hegemonic) european theoretical constructions on classroom relationships needs to be considered, as well as racism and the absence of women in the epistemic field. It is in this context that initiatives to rethink the dichotomy between reason and imagination present in westernized culture gain importance. Imagination is an important factor of psychosocial balance, it is through imagination that the whole process of symbolization, signification and dealienation of human thought takes place. Based on the notion that the imaginary and rationality are not antagonistic psychic spheres, the Pedagogy of the Imaginary proposes the reunion of rational and poetic forms of culture based on the revaluation of the imaginative function and reflection on the purpose and meaning we have given to life and education. This without resorting to a set of teaching techniques or strategies, much less taking the Pedagogy of Imaginary as a discipline whose content deals with the imagination or creativity. This study began with the completion of the discipline Pedagogy of the Imaginary in Visual Arts (2020.2/ UFPE), where the participation of students provided insights into the need to identify forms of resistance to hegemonic cultural modes, in addition to motivating us to think about a Pedagogy of the Imaginary for the Artistic Education. Some questions remain: 1) How can the knowledge about art/ life of students undergoing training in the field of teaching/ learning arts be articulated with studies on decoloniality and the Imaginary?; 2) How can the Pedagogy of the Imaginary be conceived for the field of Artistic Education and how can it be plotted with the debate on decoloniality?; 3) How do undergraduate art students think about the possibilities of deviation within their teacher training and internship practices? The doctoral project "Libertarian artistic education. A counter-pedagogy?" which began its second year in October 2021, at FBAUP, intends to continue this debate. 